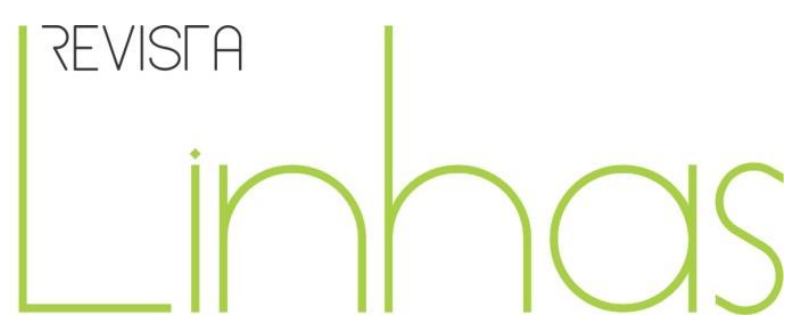

\title{
A responsabilização docente no âmbito da pedagogia das competências e habilidades
}

\section{Resumo}

O artigo em questão tem como propósito compreender como as políticas públicas nacionais no campo da Educação têm defendido a eficiência dos sistemas de ensino de Educação Básica por meio das avaliações escolares em larga escala, e identificar de que forma os/as docentes são tomados/as como 'agentes' de mudança nas instituições de ensino, num contexto histórico marcado pela ênfase na accountability. Além disso, investiga-se aqui em que medida o trabalho docente no Brasil está sendo disputado e moldado pelos organismos multilaterais (OM), contando com setores estratégicos dos aparelhos privados de hegemonia, como é o caso das mídias burguesas tradicionais. As questões aqui problematizadas encontram-se em uma conjuntura histórica marcada pelas disputas no campo curricular da Educação Básica, em que se inserem a Base Nacional Comum Curricular (BNCC) e as formulações pedagógicas hegemônicas, com destaque para a pedagogia das competências e habilidades.

Palavras-chave: Política educacional; responsabilização docente; pedagogia das competências e habilidades.

\section{Jéferson Silveira Dantas}

Universidade Federal de Santa

Catarina - UFSC - Florianópolis/SC -

Brasil

clioinsone@gmail.com

\section{Marcos Edgar Bassi}

Universidade Federal de Santa

Catarina - UFSC - Florianópolis/SC Brasil

marcos.e.bassi@gmail.com

\footnotetext{
Para citar este artigo:

DANTAS, Jéferson Silveira; BASSI, Marcos Edgar. A responsabilização docente no âmbito da pedagogia das competências e habilidades. Revista Linhas. Florianópolis, v. 22, n. 49, p. 264-288, maio/ago. 2021.
} 


\title{
Teacher accountability in competency and skills pedagogy
}

\begin{abstract}
This article aims to understand how the national public policies in the field of Education have defended the efficiency of the systems of education of Basic Education through the school evaluations in large scale and to identify in which way the teachers are taken / as agents of change in educational institutions, in a historical context marked by the emphasis on accountability. In addition, it is investigated here to what extent the teaching work in Brazil is being disputed and shaped by the multilateral organisms $(\mathrm{OM})$, counting on strategic sectors of the private apparatuses of hegemony, as they are the cases of the traditional bourgeois media. The issues discussed here are at a historical juncture marked by disputes in the curricular field of Basic Education, which include the National Curricular Common Base (BNCC) and the hegemonic pedagogical formulations, with emphasis on the pedagogy of skills and abilities.
\end{abstract}

Keywords: Educational policy; teacher accountability; pedagogy of skills and abilities. 
Os temas problematizadores apresentados neste artigo não podem ser descurados da dialética conjuntura/estrutura que assola este país há quase três décadas, especialmente com a Reforma do Estado na década de 1990 - iniciada no governo Collor de Mello (1990-1992), e acentuada nos governos do tucano, Fernando Henrique Cardoso (1995-2002) -, de cariz neoliberal e com contornos infaustos para o campo da Educação pública. Com menor força no ciclo governamental seguinte, dominado pelo Partido dos Trabalhadores, com Luiz Inácio Lula da Silva (2003-2010) e Dilma Rousseff (2011-2016), o neoliberalismo educacional não deixou de estar presente, na medida em que a política educacional referenciada no aprofundamento da avaliação em larga escala continuou moldando a gestão escolar e o trabalho docente. Por fim, em 2016, sob um golpe de Estado no Brasil nos moldes paraguaio-hondurenho, em que o vice-presidente Michel Temer (2016-2018) "usurpa" o poder, toda sorte de contrarreformas de cunho neoliberal (trabalhista, educacional e previdenciária), com o apoio estratégico de boa parte do parlamento e do judiciário nacional, além da mídia tradicional vinculada aos grupos empresariais jornalísticos, vão sendo implementadas.

Nos termos do sociólogo Michael Löwy (2018), o processo de impeachment de Dilma Rousseff representou a prática do 'golpe de Estado legal', que parece ser a nova tática das oligarquias latino-americanas. O bloco parlamentar que a destituiu da Presidência da República é formado por deputados ligados aos esquadrões da morte e às milícias privadas, aos latifundiários e criadores de gado, e aos neopentecostais integristas de viés homofóbico e misógino, muitos dos quais travestidos de socialdemocratas e liberais à brasileira. O que denotou o quanto os interesses de determinadas frações de classe são fortíssimos e perversos no Brasil. Assim, segundo Virgínia Fontes, a luta de classes nunca esteve tão vívida em território nacional, tendo em vista que

[...] a luta de classes atravessa [...] todo o conjunto da vida social e, difuso pelos aparelhos privados de hegemonia no âmbito da sociedade civil, encontra no Estado um ponto de aparente resolução, ainda que gerador de novas tensões. Não há, pois, oposição entre sociedade civil e Estado. Este seria o erro teórico liberal. (FONTES, 2010, p. 136) 
Assim e, não por acaso, o ideário neoliberal, a despeito de não ter sido abandonado, foi retomado nos últimos dois anos do contexto em destaque, com toda a sua energia após o golpe midiático-jurídico-parlamentar. Um exemplo evidente de como o renovado receituário do Consenso de Washington ${ }^{1}$, tributário daquele ideário introduzido nos países latino-americanos ainda nos anos 1990, se faz presente nas mídias tradicionais a serviço do capital; os mantras entoados diariamente nos telejornais em defesa do documento elaborado pelo Banco Mundial (2017) - Um ajuste justo: análise da eficiência e equidade do gasto público no Brasil -, objetivando convencer a população sobre a necessidade de ajustes fiscais mais severos, além de um profundo e maquiavélico ataque aos serviços públicos e, consequentemente, aos seus servidores ("privilegiados", segundo a pauta jornalística empresarial), foi um notório exemplo.

Acresce-se a essa análise o fato de que o documento do Banco Mundial (BM), assentado em referências econométricas, prescinde de uma interpretação histórica sobre a conjuntura nacional, como se o Brasil tivesse vivenciado a pleno vapor, naquilo que foi esboçado na Constituição Federal de 1988, as benesses sociais do Welfare State ou os alcunhados anos dourados do capitalismo entre as décadas de 1930 e 1970 (HOBSBAWM, 2009). Nessa direção, o documento do BM tem como enfoque o 'alívio da pobreza', com o claro intento de que rebeliões e revoltas possam ser evitadas por meio de políticas meramente compensatórias (apassivamento social). Ao mesmo tempo, procura assegurar que o Brasil possa elevar o superávit primário para continuar pagando a impagável dívida pública, retirando uma parcela cada vez maior, desviado a poucos detentores do capital financeiro improdutivo, os já parcos tributos retirados compulsoriamente da população, essenciais a investimentos em saúde e educação.

A argumentação conveniente do $\mathrm{BM}$ de que os servidores públicos são pouco produtivos e de que as soluções não são políticas, revelando tão somente o que é do interesse dos países centrais do capital, denotam o pouco rigor de suas recomendações,

\footnotetext{
1 Segundo Erminia Maricato (2015, p. 74), "com base no documento Washington Consensus de John Williamson, foi colocada em prática uma ampla estratégia de formação de quadros voltados para a tarefa de implementar o ajustamento das economias periféricas. Sua fórmula resultou de uma reunião realizada em 1989, na qual tomaram parte o governo americano [estadunidense], representantes das organizações financeiras internacionais e representantes dos países 'emergentes'. Para estes, a receita era uma só: estabilização macroeconômica com superávit fiscal primário, reestruturação dos sistemas de previdência, liberalização financeira e comercial e privatizações. Após isso tudo, a receita previa a retomada dos investimentos e o crescimento econômico, o que não ocorreu".
} 
tanto no que tange ao ponto de vista técnico-científico quanto no plano ético. Isso significa que o BM não analisa as consequências da quase ausência de tributos sobre a renda, o patrimônio, a herança e as transações financeiras; como se comportassem de maneira incauta ou distraída, os signatários do documento do BM não fazem qualquer menção às bilionárias perdas de receitas, afirmando que a equidade nas contas públicas do Brasil só pode ser alcançada com a diminuição dos 'gastos' sociais. A preocupação desse organismo internacional multilateral é com a 'eficiência', expressão utilizada mais de 120 vezes no Relatório, ainda que não haja qualquer preocupação teóricometodológica em compreender a função social da universidade ou do ensino superior público no âmbito do capitalismo dependente, desigual e combinado (LEHER, 2017).

Para Nelson Cardoso Amaral (FREITAS, 2017), não há como conferir credibilidade ao documento elaborado pelo BM, tendo em vista que os seus mentores realizam inferências, afirmações categóricas e apresentam uma realidade educacional completamente distorcida, desconsiderando a realidade social, econômica, cultural e territorial do Brasil. Já para Peter Schulz (2017), o Relatório do BM 'emula' um artigo científico, mas suas conclusões e sugestões ficam restritas à doxa, como se fossem meras notas da imprensa tradicional, que na maioria das vezes é pouco atenta à complexidade dos fenômenos sociais; ou ainda de que o documento, ao não possibilitar o contraditório, ajuda a repetir ideias que acabam sendo tomadas como 'verdades', legitimando possíveis e irremediáveis catástrofes.

Diante da reestruturação produtiva do capital de viés neoliberalizante, “expressões como inclusão e exclusão social, empregabilidade, assim como muitas outras (competências, empreendedorismo, aprendizagem ao longo da vida, empoderamento), rapidamente se constituíram em elementos estruturantes dos discursos políticos" (ALVES, 2009, p. 45) para o campo educacional. A doutrina neoliberal vincula-se à

[...] incapacidade ao longo da história do capitalismo, da teoria social, em explicar e resolver o conflito insanável entre o indivíduo, suposta e formalmente livre e em igualdade de condições, e a assimetria de poder entre as classes e frações de classes sociais. A saída neoliberal foi a criação de um decálogo de princípios doutrinários orientando a reestruturação do sistema, mediante a supressão de direitos, a privatização do patrimônio público, o retorno às teses da soberania do mercado livre de qualquer controle e a afirmação do individualismo. A 
máxima de Margareth Thatcher de que não via a sociedade, mas indivíduos, e sobre a qual busca quebrar a espinha dorsal da organização dos trabalhadores e de seus direitos, deu o sinal de largada política de ajuste neoliberal. (FRIGOTTO, 2009, p. 64)

Nestes tempos de 'indigência teórica' (FRIGOTTO, 2009, p. 72-74) e de avanço nas políticas assistencialistas e, em parte, redistributivas, sem mudanças estruturais (numa crítica aos governos petistas e sob a batuta de Luiz Inácio Lula da Silva), podem, os defensores dessas ideias, "contraditoriamente e uma vez mais, reiterar políticas personalistas e patrimonialistas que alimentam um dos projetos societários mais desiguais e violentos do mundo". Ou ainda, e pensando mais detidamente no que concerne às políticas de avaliação em larga escala, de reconversão docente e de pedagogias hegemônicas a serviço do capital (como é o caso da pedagogia das competências e habilidades), o que significa a produção ou a fabricação de um novo sujeito sob os auspícios flexibilizantes do neoliberalismo? Para Erminia Maricato,

[...]. Flexibilização é uma das marcas da mudança que se inicia nos anos 1970, visando acelerar o tempo de giro do capital: flexibilização da estrutura produtiva em relação ao território, flexibilização da organização da unidade de produção (que se fragmenta), flexibilização nas relações de trabalho, flexibilização e diversificação dos produtos, flexibilização dos mercados. A informação, o conhecimento, a marca, a mídia ganham mais importância em um mundo impactado pela velocidade, pelo efêmero, pelo espetáculo, tudo isso alimentado por significativos avanços tecnológicos. [...]. A democracia burguesa ou representativa também passa a ser contestada, assim como os partidos são esvaziados. (MARICATO, 2015, p. 71-72)

Em tal contexto e sob a baliza da individualização crescente defendida pela sociabilidade capitalista de viés neoliberal, os cientistas sociais Pierre Dardot e Christian Laval (2016) realizam uma importante investigação sobre o que denominam de 'sujeitos de um novo tipo', mais afeitos à competitividade, ao risco e à busca da eficácia das suas iniciativas e desejos personalistas. Segundo os autores, “o efeito procurado pelas novas práticas de fabricação e gestão do novo sujeito é fazer com que o indivíduo trabalhe para a empresa como se trabalhasse para si mesmo" (DARDOT; LAVAL, 2016, p. 327), ou seja, a racionalidade neoliberal estaria produzindo sujeitos preocupados com a maximização de 
seus resultados, expondo-se a riscos e assumindo inteiramente a responsabilidade por eventuais fracassos.

O discurso gerencial ganha tal dimensão que esse 'novo sujeito' é visto como proprietário de capital humano, que ele precisa acumular por meio de um cálculo responsável entre custos e benefícios. Em outras palavras, a distribuição dos recursos econômicos e das posições sociais é vista exclusivamente como consequência de percursos bem ou malsucedidos, diferenciando os riscófilos(os que têm gosto pelo risco e potenciais empreendedores) dos riscófobos (os que têm medo de arriscar, mais afeitos aos ofícios tradicionais). Os 'gestores do risco' seriam mais adaptáveis e suscetíveis à intensificação do desempenho. Não por acaso, a figura do coaching é tão difundida nos dias de hoje, como apontam os cientistas sociais: "Foi esse modelo mais do que o discurso econômico sobre a competitividade que permitiu naturalizar esse dever do bom desempenho e difundir nas massas certa normatividade centrada na concorrência generalizada" (DARDOT; LAVAL, 2016, p. 353-354).

A obra de Dardot e Laval nos faz refletir sobre o significado da neogestão, calcada no controle dos comportamentos e atitudes dos trabalhadores, que diante do enfraquecimento dos coletivos de trabalho, isolam-se e internalizam fracassos. Tal discurso da 'realização de si mesmo' e de 'sucesso na vida' leva a uma estigmatização dos 'perdedores', 'perdidos', isto é, dos incapazes de se adaptarem à nova norma social de felicidade. O fracasso social é visto, em última instância, como uma patologia. Concluem os autores que parece ser inútil lamentar a crise das instituições (família, escola, organizações sindicais) e tentar compreender como todas essas instituições são hoje incorporadas e transformadas em dispositivos de desempenho/eficácia em nome da modernização. Ou ainda, “oscilando entre depressão e perversão, o neosujeito é condenado a ser duplo: mestre em desempenhos admiráveis e objeto descartável" (DARDOT; LAVAL, 2016, p. 374).

Nas seções seguintes, procuraremos compreender como a 'fabricação do sujeito neoliberal' tem alterado os modelos de avaliação escolar e as práticas pedagógicas dos trabalhadores em educação, corroboradas com a assertiva fatalista de que a polivalência, a despolitização, a adaptação funcional e o espírito empreendedor são os motes necessários para se forjar um/a bom/a professor/a na escola pública brasileira. 


\section{A responsabilização docente num contexto de contrarreformas}

Não é possível descolarmos as questões que envolvem a avaliação escolar, em todos os seus níveis e modalidades de ensino, de seu desenho ou orientação curricular. Isso significa que os processos avaliativos estão açambarcados por dimensões políticas, culturais, ideológicas e econômicas (DANTAS, 2017). Michael Apple (2002) tem formulado proeminentes discussões referentes à reorientação curricular nos EUA, que encontram associações ao que vem ocorrendo em nosso país em tempos de imposição de uma Base Nacional Comum Curricular (BNCC). Apple identifica em um de seus estudos determinadas alianças sociais e econômicas que estariam ameaçando situações de igualdade nos territórios educativos, sob o verniz do 'discurso da melhoria da competitividade' e do aumento dos postos de trabalho. Tais alianças de classe se configuram em quatro grandes 'facções' nos termos de Apple: 1) neoliberais; 2) neoconservadores; 3) populistas autoritários e 4) classe média profissional.

Para o primeiro grupo (neoliberais), as escolas públicas são vistas como 'buracos negros', sem resultados adequados; os estudantes são encarados como capital humano, e qualquer investimento que não seja o estritamente econômico é compreendido como 'suspeito'. Em outras palavras, as tomadas de decisão aparentam dar a todos iguais oportunidades de escolarização, todavia, transformando as responsabilidades das tomadas de decisão da esfera pública para a esfera privada, reduzindo a ação coletiva e/ou popular que garanta, efetivamente, a qualidade de educação para todos. Os neoliberais do campo da educação têm uma fé essencial na lealdade e justiça dos mercados, porém, essas estratégias economicistas e despolitizadoras acabam por elevar as crescentes desigualdades de recursos e poder.

Já os neoconservadores, que podem ser facilmente vinculados aos adeptos do movimento Escola sem Partido², entendem que não é o mercado que resolverá os problemas do currículo escolar, mas um Estado interventor que garantirá apenas os conteúdos e métodos 'legítimos' a serem ensinados e utilizados. Em síntese, incorre-se na ideia de um currículo único, que defenda os valores tradicionais (dos imigrantes brancos) e sem o reconhecimento da luta de classes. E o mais grave: a defesa de um determinismo

\footnotetext{
2 Sobre o tema, indicamos a seguinte leitura: FRIGOTTO, Gaudêncio (org.). Escola sem partido: esfinge que ameaça a educação e a sociedade brasileira. Rio de Janeiro: UERJ, 2017.
} 
genético ou racial na capacidade de aprendizagem dos/as estudantes. Coadunado a esse pensamento reacionário, o populismo autoritário, assentado na direita cristã, entende que as questões de gênero e a ideia de família são unidades divinas e orgânicas, que resolvem por si só, sem mediações históricas, o ‘egoísmo masculino' e o 'altruísmo feminino'. Por fim, a chamada 'classe média profissional' (ideologicamente contraditória, segundo Apple), por meio da defesa das charter schools, ou seja, escolas públicas mantidas por meio de gerenciamento privado, preocupadas tão somente com os resultados acadêmicos nas disciplinas tradicionais e no ensino prático tradicional, são muito suscetíveis a uma ordem discursiva aparentemente inclusiva, mas que oculta opressões, preconceitos e estereótipos.

Para Pimenta (2018, p. 47-48), com a Reforma do Estado brasileiro a partir da década de 1990 e apoiado nos estudos de João Zanardini (2008), o Estado nacional passa a se assentar na concepção de 'Estado avaliador', regulando e controlando as políticas educacionais. A redução dos investimentos públicos em Educação se evidenciaria ainda na emergência de novos nichos para o capital, por meio da privatização explícita em políticas de apostilamento (materiais ou recursos pedagógicos produzidos pela esfera privada), além de consultorias educacionais e reformas no ensino superior. Em outras palavras, tais mudanças nos processos avaliativos objetivavam e objetivam a "capacidade da escola para educar para a flexibilidade, para a resolução de problemas e para a produção de ideias criativas, características tomadas como necessárias à globalização e ao alívio da pobreza" (ZANARDINI, 2008, p. 133 apud PIMENTA, 2018, p. 48).

Segundo Sousa (2003), os processos de avaliação externa em larga escala (SAEB, ENEM, PROVA BRASIL) condicionam os currículos, intensificando desigualdades escolares e sociais, embora desde a década de 1980 já aparecessem as primeiras tentativas de se avaliar de forma mais sistemática a qualidade da Educação Básica brasileira.

A presença das avaliações externas ganhou proeminência após o desdobramento do SAEB, em 2005, em duas avaliações complementares: a Avaliação Nacional do Rendimento Escolar (ANRESC), mais conhecida pelo nome de PROVA BRASIL, e a Avaliação Nacional da Educação Básica (ANEB). Ambas têm como objeto a avaliação de língua portuguesa (leitura) e matemática (resolução de problemas), mediante provas com itens de múltipla escolha aplicados em alunos de $4^{\mathrm{a}}$ e $8^{\mathrm{a}}$ séries de ensino 
fundamental e $3^{\text {a }}$ séries do Ensino Médio. (ALAVARSE; BRAVO; MACHADO, 2013, p. 17)

O Decreto 6.074/2007, durante o governo Lula (2003-2010), implantou em todo o país o IDEB (Índice de Desenvolvimento da Educação Básica), referente ao Plano de Metas Compromisso Todos pela Educação. O IDEB cruza os resultados de desempenho nas provas do SAEB com as taxas de aprovação de cada uma das unidades escolares e redes de ensino, sendo de responsabilidade do INEP (Instituto Nacional de Estudos e Pesquisas Educacionais Anísio Teixeira) a divulgação desses resultados. A justificativa das avaliações externas estaria acalcanhada na necessidade de

[...] monitorar o funcionamento das redes de ensino e fornecer aos seus gestores subsídios para a formulação de políticas educacionais com focos mais bem definidos em termos de resultados que, por sua vez, decorram da aprendizagem dos alunos. [...]. Deve-se destacar que essas avaliações externas têm como característica, entre outras, a definição de uma matriz de avaliação - na qual são especificados os objetos de avaliação e o emprego de provas padronizadas, condição para que sejam obtidos resultados mais objetivos e efetuadas comparações entre redes e escolas, tanto transversal quanto longitudinal. (ALAVARSE; BRAVO; MACHADO, 2013, p. 17)

Ainda que tenhamos concordância de que a avaliação do trabalho pedagógico é fundamental para que possamos compreender os resultados dos itinerários formativos dos estudantes, por outro lado, temos de compreender que as avaliações externas em larga escala também têm sido utilizadas para submeter os professores a uma imensa pressão, retirando-lhes a autonomia profissional e impedindo-lhes de desenvolver um trabalho pedagógico consistente e consequente do ponto de vista conceitual, político e humano. Essas políticas públicas de responsabilização (accountability) acabam por favorecer, ao fim e ao cabo, a lógica meritocrática e a culpabilização dos professores, ferindo preceitos democráticos. Acirra-se, desse modo, uma competição entre as escolas e um processo de ranqueamento que empobrece o conjunto das atividades pedagógicas desenvolvidas nesses territórios educativos. 
Nessa perspectiva, segundo Sousa (2003, p. 181), os conteúdos a serem ensinados na escola são os mesmos que serão 'cobrados' pelas avaliações em larga escala, atribuindo ao potencial do/a estudante o seu "sucesso pessoal e profissional, abstraindo os fatores econômicos e sociais" (SOUSA, 2003, p.182). Em outras palavras,

As políticas educacionais ao contemplarem em sua formulação e realização a comparação, a classificação e a seleção incorporam, consequentemente, como inerentes aos seus resultados a exclusão, o que é incompatível com o direito de todos à educação. (SOUSA, 2003, p. 188)

Já Fernandes pondera que as escolas públicas passaram a ser exigidas a partir de uma 'lógica empresarial', na qual os resultados são mais importantes que o processo de ensino e aprendizagem:

Podemos dizer que chegamos à educação do treino e do produto. Todos os meios justificariam os fins: obter um alto Índice de Desenvolvimento da Educação Básica (IDEB). A promessa é de que isso nos colocará no topo e conquistaremos uma educação de qualidade [...]. Para as políticas que se baseiam nos exames de larga escala, os processos importam muito pouco. A avaliação é vista como possibilidade de medição de um conhecimento que, por sua vez, pode ser medido, destituído de qualquer complexidade e subjetividade. Importa um currículo enxuto, um bom treinamento, um 'professor tarefeiro' e um 'aluno marca $x$ '. (FERNANDES, 2015, p. 402)

Nessa esteira, há os que defendem as políticas de 'bônus por desempenho docente' e a 'meritocracia' como elementos de elevação da qualidade em educação. Não por acaso, os organismos internacionais multilaterais são pródigos em estudos que procuram articular carreira doente e 'desempenho efetivo' em sala de aula. Segundo a uruguaia Denise Vaillant (2011, p. 5), Doutora em Educação e consultora da UNESCO, países como Argentina, Brasil, Chile, Colômbia e Peru só podem melhorar os seus resultados educacionais a partir da "combinação dos méritos e dos resultados das provas [já que as mesmas] determinam a seleção e a ordenação dos docentes". No que tange ao Brasil, especificamente, Vaillant utiliza como modelo de referência o estado de São Paulo, onde o bônus por desempenho docente, a meritocracia e a concorrência escolar já foram internalizados de maneira mais explícita, lembrando que São Paulo teve à testa, desde 
meados dos anos 1990, governos capitaneados pelo Partido da Social Democracia Brasileira (PSDB).

Denise Vaillant se mostra surpresa em seu relatório técnico, diga-se de passagem, bastante prescritivo/descritivo e pouco analítico, com a baixíssima adesão dos docentes às políticas de bônus por desempenho: "O que parece ser uma constante na América Latina e no Caribe é que cada vez que se propõe fazer uma avaliação com caráter sistemático, a primeira reação dos docentes é considerá-la uma espécie de ameaça" (VAILLANT, 2011, p. 15). Ora, a consultora, ao estabelecer uma razão cínica em seu empreendimento analítico, não faz qualquer mediação sobre o impacto de tais políticas no que tange aos problemas históricos do dualismo educacional ${ }^{3}$ no Brasil e demais países da América Latina. Sua defesa em relação às 'premiações focalizadas' apenas acirra competitividades no território educativo, e não há qualquer menção aos planos de carreira, concursos públicos regulares e valorização salarial do magistério.

Na mesma direção de Vaillant, o pesquisador britânico Nigel Pelham de Leighton Brooke, graduado em Psicologia Experimental, assessor e representante da Fundação Ford no Brasil entre 1994 e 2003, além de professor convidado da Faculdade de Educação da UFMG para tratar de avaliação e medidas educacionais em 2017, entende que falta a países como o Brasil uma 'filosofia de accountability'. Segundo as suas palavras,

[...]. Estas análises dividem o conceito de accountability em dois componentes. O primeiro de 'prestação de contas', seria típico das democracias anglo-saxãs, nas quais a noção de cidadania se confunde com o pagamento de impostos e o direito de todos de cobrar o bom uso do dinheiro público. O segundo de 'responsabilização', tem o sentido de atribuir aos funcionários públicos uma parte da responsabilidade pelos resultados alcançados. A nossa tradução da palavra accountability por responsabilização, correspondendo a somente uma parte do significado original sinaliza a adaptação do conceito a uma cultura política diferente. (BROOKE, 2013, p. 101)

Brooke defende a tese de que a remuneração docente deve se dar por resultados ou por incentivos de desempenho com ganhos de remuneração variável (high stakes), alcunhando os críticos das políticas de responsabilização docente como 'doutrinários'.

\footnotetext{
3 Sobre o tema Cf. Libâneo (2012).
} 
Para esse pesquisador, "a competição interinstitucional pode fornecer uma motivação criativa que em nada danifica as relações interpessoais entre membros da equipe escolar e muito menos as relações entre professor e aluno" (BROOKE, 2013, p. 111). Como o autor parte do pressuposto de que os testes padronizados são essenciais para se elevar a qualidade educacional, rebate toda e qualquer crítica que enxerga em tais avaliações em larga escala a restrição dos conteúdos a serem ensinados na Educação Básica. Para tanto, abaliza que não há pesquisas consistentes sobre a responsabilização docente no Brasil, o que impediria uma "avaliação objetiva da política e a projeção de cuidados necessários para minimizar os efeitos indesejáveis" (BROOKE, 2013, p. 120).

Por seu turno, Luiz Carlos de Freitas (2013, p. 122-123) assinala que a proclamada 'igualdade de oportunidades' na Educação Básica justificaria a 'desigualdade de resultados' no desempenho discente, ganhando relevo "o uso do resultado da avaliação e não o processo submetido à avaliação". Ao problematizar e politizar o debate, diferentemente de Vaillant e Brooke, Freitas compreende que a valorização dos resultados educacionais é "transmutada em premiação dos melhores e afastamento dos piores". A educação vai se convertendo num jogo de ganhadores e perdedores bem a gosto da lógica dos negócios (FREITAS, 2013, p. 123). De maneira explícita, Freitas vaticina quem são os mentores dessas políticas de avaliação em larga escala:

[...]. O cérebro desta ideologia é o Movimento Todos pela Educação [grifos nossos] que é uma agremiação constituída e financiada por grandes empresários destinada a criar uma legislação favorável a suas teses e a afetar a política pública. Declara-se apartidário ou suprapartidário, mas sempre que pode coloca seus seguidores em postos chaves do governo. (FREITAS, 2013, p. 124)

Se a agenda educacional brasileira nos dias de hoje está sendo disputada pelos educadores profissionais e os reformadores empresariais da educação, devem-se reconhecer igualmente, e de acordo com o autor, os limites da ideologia educacional vinculados a uma racionalidade neoliberal ${ }^{4}$, traduzidas em dez tópicos: 1 ) estreitamento

\footnotetext{
4 Com a adequação da Base Nacional Comum Curricular (BNCC) aos testes padronizados, padronizam-se também as práticas pedagógicas, o apostilamento dos materiais pedagógicos com a consequente desistência dos coletivos escolares de seu papel de protagonismo na formulação dos projetos políticos escolares. Enfim, criam-se todas as formas de privatização da educação pública e a desqualificação de seus
} 
curricular; 2) competição entre profissionais; 3) pressão sobre o desempenho dos alunos e preparação para os testes; 4) fraudes; 5) aumento da segregação socioeconômica no território; 6) aumento de segregação socioeconômica dentro da escola; 7) precarização da formação do professor; 8) destruição moral do professor e do aluno; 9) destruição do sistema público de ensino; 10) ameaça à própria noção liberal de democracia.

Os pontos assinalados anteriormente se agudizam em tempos de fascistização sobre temas ou questões estruturais da vida pública no Brasil. Freitas é taxativo ao relatar que não há atalhos para a boa educação e de que a necessidade de reverter as políticas de avaliação supranacionais de comprovado fracasso, exigiria uma responsabilização de conotação participativa. De fato, após a ditadura civil-militar (1964-1985) ainda se podia discernir nas políticas educacionais duas visões de educação: uma que tinha como meta a democracia e as oportunidades sociais e outra que preparava as pessoas para o mundo do trabalho numa perspectiva individualista. Tais disputas educacionais geraram em vários estados a construção de propostas curriculares conectadas a uma perspectiva crítica, especialmente na segunda metade da década de 1980. Já na década de 1990, com o impacto do neoliberalismo e o fim do denominado 'socialismo real', desmoronaram-se as aspirações por uma educação centrada no ser humano e em seu desenvolvimento e se impôs a hegemonia da educação pragmática/utilitarista, por meio de políticas imediatistas de formação de sujeitos centradas na rentabilidade econômica e, com ela, a ascensão das pedagogias hegemônicas (construtivismo, pedagogia de projetos, pedagogia das competências, etc.). É o que discutiremos na próxima seção do artigo em tela.

\section{A pedagogia das competências e habilidades: mais do mesmo da política neoliberal para a educação brasileira}

No que tange às diferentes concepções ou formulações teóricas pedagógicas e às suas disputas no processo formativo docente na Educação Básica, a 'pedagogia das competências e habilidades' se insere nas denominadas pedagogias hegemônicas que, segundo Dermeval Saviani (2008), corresponde aos interesses dominantes e, portanto, 
tendem a hegemonizar o campo educativo. Dantas (2009) identificou que a pedagogia das competências e habilidades vem desde a década de 1990 tensionando tais disputas nos campos do currículo e da avaliação escolar, tendo como marco inaugural o discurso da qualidade total, estreitamente vinculado à reestruturação produtiva do capital.

Somado a isso, ao nos referirmos às teorias pedagógicas hegemônicas, estamos discutindo as correntes pedagógicas associadas ao slogan 'aprender a aprender', das quais fazem parte ainda o construtivismo, a pedagogia do professor reflexivo, a pedagogia dos projetos, a pedagogia multiculturalista e aquela que originou o 'aprender a aprender': o escolanovismo (SANTOS, 2013). Tais configurações pedagógicas ganharam terreno a partir do relatório apresentado pela UNESCO em 1996 e intitulado Educação: um tesouro a descobrir, coordenado por Jacques Delors, que foi presidente da Comissão Europeia entre as décadas de 1980 e 1990. O documento defendia, dentre outros princípios, a ideia de que um conjunto de saberes era necessário para a adaptação funcional dos indivíduos num mundo cada vez mais incerto e competitivo. 0 esvaziamento do conteúdo escolar e, consequentemente, a desqualificação e a desintelectualização do trabalho docente são tomados como projetos deliberados dessas formulações pedagógicas hegemônicas; reduz-se a escola a um espaço de acolhimento ou de socialização, sem qualquer proposição pedagógica. E mais preocupante: um espaço de contenção dos filhos da classe trabalhadora.

A gestão da qualidade total (GQT) na educação brasileira foi implementada durante o governo Collor de Mello (1990-1992), quando se promoveu a denominada 'década da qualidade total na educação brasileira' (1993-2003). Tal proposição se vinculava ao meio produtivo representado pelas fábricas automotoras japonesas (toyotismo), que tinham como características o estilo gerencial e a cultura da qualidade; estudantes e familiares passam a ser clientes em tal processo educacional. No Brasil, a principal mentora desse ideário foi a educadora Cosete Ramos, Doutora em Educação nos EUA e especialista em gestão da qualidade total. Como técnica e dirigente, Ramos trabalhou por mais de 20 anos no MEC, exercendo na década de 1990 a função de coordenadora-adjunta do Núcleo Central da Qualidade e Produtividade no governo Collor de Mello. Além disso, exerceu o cargo de suplente do Ministro da Educação, Murilo de Avelar Hingel, no Comitê Nacional 
de Qualidade e Produtividade - Programa Brasileiro de Qualidade e Produtividade (DANTAS, 2009, p. 69).

Destarte, a preparação de um professor mais 'competente', acompanhado do discurso da 'qualidade' nos idos da década de 1990, trazia à baila o pressuposto escolanovista com pequenas alterações, ou seja, com a universalização do Ensino Fundamental, os mais capacitados poderiam prosseguir seus estudos em níveis ulteriores, revelando as 'lideranças naturais' na sociedade capitalista (DANTAS, 2009, p. 77). 0 darwinismo social naqueles anos estimulava a competitividade, a flexibilização no mundo do trabalho e a pretensa derrubada de fronteiras geográficas e ideológicas.

A capacidade de adaptar-se passou, então, a ser a palavra de ordem; no meio educacional, esse ‘novo modelo de trabalhador' passou a ser identificado por meio de um profissional mais competente e com habilidades específicas para resolver situaçõesproblema em seu cotidiano escolar, demandando um saber-fazer. Em síntese, saberes, habilidades e competências formariam a tríade do novo perfil do professor nos anos 1990. Esse profissional dos 'novos tempos' precisava ser mais criativo, pois o mundo do trabalho de então exigiria profissionais capazes de tomarem decisões imediatas, ao mesmo tempo em que necessitavam de profissionais com espírito de liderança e que não se responsabilizassem por uma única tarefa pedagógica (DANTAS, 2009, p. 86).

A pedagogia das competências e habilidades foi pródiga também no governo Fernando Henrique Cardoso (1995-2002), especialmente em propostas curriculares de referência nacional, como eram os casos dos Parâmetros Curriculares Nacionais (PCN). A Base Nacional Comum Curricular (BNCC), formulada após o golpe de 2016, sustentada nessa pedagogia, teve o apoio fundamental do empresariado nacional e de institutos privados por meio do 'Movimento pela Base Nacional Comum'. O documento intitulado 'Dimensões e desenvolvimento das competências gerais da BNCC' (2018), elaborado por esse grupo de empresários, por exemplo, defende 10 competências gerais que devem transversalizar a BNCC, a saber: 1) conhecimento; 2) pensamento científico, crítico e criativo; 3) repertório cultural; 4) comunicação; 5) cultura digital; 6) trabalho e projeto de vida; 7) argumentação; 8) autoconhecimento e autocuidado; 9) empatia e cooperação; 10) responsabilidade e cidadania. 
Contudo, de todas as competências acima, as que vêm ganhando cada vez mais visibilidade ou destaque são aquelas identificadas nos tópicos 8, 9 e 10, que estão inextricavelmente associadas à competência socioemocional. E é sobre ela que trataremos mais detidamente. Segundo Jane Eire Rigoldi dos Santos (2015), não se pode descolar as avaliações em larga escala da pedagogia das competências e habilidades, levadas a cabo e com muita aderência por parte de governos municipais que adotam modelos formativos de institutos privados, como é o caso do Instituto Ayrton Senna (IAS). No que tange às competências socioemocionais, Santos destaca que:

No Brasil, a avaliação elaborada pelo Projeto SENNA é um dos primeiros esforços políticos para a formulação de avaliações de atributos de personalidade. Ela ocorreu em outubro de 2013, no Rio de Janeiro, como um projeto piloto, que avaliou 24.605 alunos, sob a coordenação e parcerias do Instituto Ayrton Senna (IAS), Centro de Pesquisa e Inovação Educacional (CERI), direcionado pela OCDE, MEC e o governo do Rio de Janeiro. Essa avaliação, criada por experts é diferente de avaliações tradicionais, porque está voltada a avaliar atributos da personalidade humana, atributos complexos para serem medidos, por serem abstratos. Nos documentos, a avaliação do Projeto SENNA recebeu uma infinidade de nomes, como avaliação de competências, de habilidades não cognitivas,sociais, emocionais, afetivas, socioemocionais, etc.(SANTOS, 2015, p. 46-47)

Uma competência socioemocional que atenda à sociabilidade capitalista, segundo as problematizações e mediações teóricas apresentadas por Santos (2015, p. 62-63), denota que a pobreza não é um problema a ser superado, mas sim o estresse que prejudica a formação do caráter. À escola caberia atuar no sentido de aconselhar os jovens que se encontram em situação de vulnerabilidade social e que pudessem vir a cometer algum tipo de delito no futuro. Deve-se ensinar crianças e jovens a serem resilientes diante das condições adversas ou precárias da vida. O otimismo e a resiliência ganham muito mais espaço do que os conteúdos escolares; aulas sobre caráter, escrúpulos, determinação e perseverança são vistas como um 'conjunto de valores' a serem perseguidos pela escola, notadamente, as escolas públicas.

Ainda segundo estudos de Silva (2018) as competências socioemocionais vêm sendo introduzidas nos espaços educativos públicos, notadamente, por institutos 
privados, destacando-se o Instituto Ayrton Senna (IAS). As competências socioemocionais estariam enquadradas nas denominadas competências não cognitivas. Apoiado em materiais pedagógicos elaborados pelo IAS, Silva destaca que:

Do conjunto de competências que podem ser formadas, as competências socioemocionais são aquelas empregadas "para se relacionar com os outros e consigo mesmo, compreender e gerir emoções, estabelecer e atingir objetivos, tomar decisões autônomas e responsáveis e enfrentar situações adversas de maneira criativa e construtiva". As competências cognitivas, por outro lado, são aquelas que se empregam "para interpretar, refletir, raciocinar, pensar abstratamente, assimilar ideias complexas, resolver problemas e generalizar aprendizados". (IAS, 2016 apud SILVA, 2018, p. 47, grifo do autor)

Vão ficando nítidas as estratégias desses institutos privados em capturar a subjetividade da classe trabalhadora, que têm por referências processos avaliativos determinados por organismos internacionais multilaterais, sobretudo a UNESCO e a OCDE. Além disso, a lógica do capital está atenta à importância dos vínculos afetivos com as famílias e à formação de competências socioemocionais desde tenra idade ou na 'primeiríssima infância', assentada em estudos do economista estadunidense, James Heckman, Nobel de economia em 2000, nos quais ele afirma que para cada dólar investido na primeira infância, obtém-se um retorno de sete dólares na vida adulta (SILVA, 2018, p. 55). Isso garantiria capitais humanos mais sólidos ou consistentes e economia com gastos em doenças evitáveis, evasão escolar e episódios de violência.

O que pode aparentar um cuidado zeloso e imparcial em relação aos seres sociais em formação, oculta a necessidade de o capital tornar os indivíduos totalmente disponíveis para venderem a sua força de trabalho. A OCDE corrobora esse ideário ao identificar que as competências socioemocionais poderiam evitar situações de obesidade, depressão, problemas de conduta, ingestão de álcool, tabagismo, uso abusivo de substâncias tóxicas, bullying etc. Em outras palavras, a OCDE entende que responsabilidade, perseverança e confiabilidade são aspectos impulsionadores de sucesso na vida (SILVA, 2018, p. 63).

A razão cínica da lógica do capital despreza ou desconsidera, olimpicamente, que todas as mazelas sociais são de outra ordem e, portanto, não redutíveis a aspectos de 
ordem socioemocional. Como se não bastassem todas as ações estratégicas dos organismos internacionais multilaterais para 'alívio da pobreza' nos países periféricos do capital, as competências socioemocionais vão se apresentando como novos argumentos cínicos, geradoras de uma ilusória igualdade de condições nos terrenos educativos, quando se sabe que as perversas desigualdades de ordem social/econômica reproduzem em variados níveis, desigualdades escolares. Eis, então, mais uma das tantas táticas do capital, que agora se direcionam à captura da subjetividade da classe trabalhadora para a produção de consensos ativos.

\section{Considerações finais}

O que o nosso breve percurso de análise nos permitiu compreender é que a avalanche de contrarreformas, inspiradas no ideário neoliberal após o "golpe de Estado legal” em 2016, reforça a substituição de políticas de valorização docente por políticas de responsabilização docente, como receita para a eficiência dos resultados escolares. A possibilidade de implementação de políticas meritocráticas e individualistas de bonificação e de penalização pelos resultados escolares e o denuncismo em sala de aula representado pelo conservadorismo retrógrado do movimento Escola sem Partido se articulam no novo contexto político e encontram espaço favorável para avançar.

A eleição em 2018 de um político de extrema-direita para a Presidência da República - o capitão reformado do exército, Jair Messias Bolsonaro, no mandato 2019-2022 -, situação replicada em vários governos estaduais, concretiza o quadro vislumbrado por Apple (2002) para o contexto estadunidense, ou seja, um representante do populismo autoritário enlaça as pontas do neoliberalismo e do conservadorismo, com amplo apoio da classe média profissional e, acrescente-se, da elite dominante e de grande parcela da população, instaurando um triste cenário de retrocesso na educação e na sociedade brasileira.

Segundo o historiador Timothy Snyder (2017, p. 23),

[...] temos uma tendência de imaginar que as instituições são capazes de se proteger de forma automática até dos ataques mais diretos [...]. $\mathrm{O}$ erro está em presumir que os governantes que chegaram ao poder por meio das instituições não possam mudar ou destruir essas mesmas 
instituições - mesmo no caso daqueles que anunciaram que fariam exatamente isso. (SNYDER, 2017, p. 23)

Nessa direção, não há por que se enganar, deliberadamente. As instituições públicas, como é o caso das escolas de Educação Básica, são espaços basilares de construção de conhecimento e também de resistência; são ainda os únicos espaços em que a população pobre pode ser atendida de maneira gratuita e com o compromisso público requerido por meio de seus servidores. Ora, há por que se dar um voto de confiança para quem, desde o princípio, defendeu a privatização de empresas e escolas públicas e de que os patrões/empregadores são 'vítimas' dos trabalhadores, já que esses últimos têm (pasmem!) tantos direitos?

Por seu turno, tais retrocessos históricos encerram reorganizações curriculares e padronizações formativas, retirando dos professores e professoras, sobretudo, a proposição de práticas didáticas que possam colocar em xeque valores e/ou concepções atinentes à lógica do capital. A tentativa de retomada das disciplinas cívicas, por exemplo, de triste lembrança e herança nefasta do período da ditadura civil-militar no Brasil (19641985) foram aventadas por um ministro que se mostrou despreparado para o posto que fora indicado, aliás, indicação de um pretenso filósofo de internet que reside nos EUA.

O Brasil não conseguiu até hoje universalizar o acesso de crianças e jovens a todas as etapas da Educação Básica. E o que isso significa? Uma massa de jovens inseridos no mundo do trabalho com uma formação simples para o trabalho simples; com compreensões restritas sobre o conhecimento histórico, incapazes de diferenciar comunistas de fascistas; incapazes de reconhecer seus próprios dramas e dilemas de filhos e filhas da classe trabalhadora, sem qualquer discernimento da realidade concreta.

Como bem assevera Luiz Carlos de Freitas (2018, p. 908),

Neste redemoinho, entender o inimigo (e não o subestimar) pode ser um bom começo. O termo usado foi "inimigo" porque há que distingui-lo de "adversário". No primeiro caso, um inimigo é aquele que quer eliminá-lo por se contrapor a ele; no segundo caso, estamos no âmbito de um confronto entre pessoas que se respeitam mutuamente, apesar de discordarem - típico das democracias liberais. (FREITAS, 2018, p. 908, grifo do autor) 
O modelo da democracia liberal parece ter chegado ao seu esgotamento como projeto. Freitas complementa:

O projeto educacional progressista, no Brasil, durante as últimas décadas, ficou emparedado entre estas duas proposituras (a social democrata e a pós-moderna). Ambas se esgotaram e não têm condições de liderar uma resistência propositiva. Pela primeira, seríamos reduzidos à defesa da velha democracia liberal já cambaleante; pela segunda, teríamos uma resistência niilista, portanto, sem projeto histórico, já que para os últimos as metas narrativas não têm utilidade. A coalizão que foi vitoriosa nas eleições de 2018, liderada por Bolsonaro, é novamente uma combinação de duas filosofias sociais: conservadorismo e liberalismo. Conservadores podem ser autoritários quanto à forma de governo, mas os liberais têm se caracterizado, em tese, pela defesa da democracia liberal. A surpresa é que nesta nova fase que se abre com Bolsonaro, os liberais também se apresentam com uma face autoritária. Temos, agora, uma coalizão de conservadores e liberais que se unem em uma forma autoritária de governar - tendo como ponto de origem o golpe contra uma presidenta eleita concretizado em 2016. (FREITAS, 2018, p. 909)

Isso nos parece bastante relevante, caso queiramos compreender não apenas mudanças de caráter curricular nas escolas e em seus respectivos processos formativos e avaliativos, ainda que os mesmos sejam essenciais ao se analisar, detidamente, os efeitos de uma Base Nacional Comum Curricular que teve discussão quase nula nas universidades públicas e associações de classe. Em outras palavras, os neoliberais ou ultraliberais podem prescindir da democracia para fazerem valer os seus interesses.

Associada a essa tese, qual seja, a do esgotamento do modelo liberal democrático, temos hoje no Brasil mais coisas para nos preocupar:

Provavelmente o que nos choca, agora, é a defesa explícita e aberta das teses do liberalismo econômico autoritário em associação com o conservadorismo, de maneira organizada e militante, formando uma frente jurídica, parlamentar e midiática em defesa delas e que não hesita em fazer uso de recursos jurídicos ilícitos ("lawfare") contra quem considere ser seu inimigo. A insegurança jurídica torna-se mecanismo de censura e ameaça difusa, perpassando toda a sociedade, em um processo crescente de "judicialização" da vida social, em substituição à própria política. (FREITAS, 2018, p. 919 apud CHAUÍ, 2018, grifo do autor)

Além do "lawfare", a atuação destas forças inclui: limitar ou dificultar o voto do cidadão, ou pelo seu oposto, facilitar para que o cidadão não se 
manifeste nas eleições (voto não obrigatório, por exemplo); impedir os processos de organização social dos mais desfavorecidos; não transferir impostos para os menos favorecidos e barrar os processos de redistribuição de renda; destruir a organização dos trabalhadores, a atuação dos sindicatos e confederações; destruir a atuação e organização dos movimentos que lutam pelos direitos humanos; atuar contra os imigrantes e contra ações de preservação do meio ambiente; desregulamentar a atuação das corporações; privatizar tudo que for possível; propor formas de proteção constitucional quase que irrevogáveis, que evitem o impacto de eventuais decisões contrárias ao livre mercado, entre outras. Tudo isso em alto e bom som. (FREITAS, 2018, p. 919, grifo do autor)

Freitas (2018), por fim, considera ser um erro estratégico o combate ao movimento Escola sem Partido (possivelmente, uma mera cortina de fumaça), pois o que se evidencia, explicitamente, é a privatização da educação pública. E essa, segundo Freitas, deveria ser a agenda de resistência a partir de agora, ou seja, o combate à privatização das escolas públicas desde a Educação Básica até o Ensino Superior. O que se vê, efetivamente, é uma reforma empresarial na educação brasileira, regulada pelo mercado e a tentativa de suplantar as contradições e os dissensos.

Logo, ao fazermos tais considerações, entendemos que nos últimos 50 anos já vivenciamos contextos tão ou mais complexos do que este que se estabelece. Abre-se, portanto, um período de resistência, reflexão, de crítica e autocrítica que pode (e deve) fortalecer a luta política, contribuindo para a retomada de um efetivo caminho democrático. 


\section{Referências}

ALAVARSE, Ocimar M; BRAVO, Maria Helena; MACHADO, Cristiane. Avaliações externas e qualidade na Educação Básica: articulações e tendências. Estudos de Avaliação

Educacional, São Paulo, v. 24, n. 54, p. 12-31, jan./abr. 2013. Disponível em:

http://publicacoes.fcc.org.br/index.php/eae/article/view/1900. Acesso em: 17 set. 2018.

ALVES, Natália. Por que está a escola incumbida de promover a inclusão e a empregabilidade? In: CANÁRIO, Rui; RUMMERT, Sonia Maria (orgs.). Mundos do trabalho e aprendizagem. Lisboa: Educa, 2009, p. 45-60.

APPLE, Michael. "Endireitar” a educação: as escolas e a nova aliança conservadora. Currículo sem fronteiras, [s.l.], v.3, n. 1, p. 50-59, jan./jun. 2002. Disponível me: http://www.curriculosemfronteiras.org/vol2iss1articles/apple.htm. Acesso em: 17 set. 2018.

BANCO MUNDIAL. Um ajuste justo: análise da eficiência e equidade do gasto público no Brasil, v. 1. [S.I.], nov. 2017. Disponível em: https://www.worldbank.org/pt/country/brazil/publication/brazil-expenditure-reviewreport. Acesso em: 17 set. 2018.

BROOKE, Nigel. Políticas estaduais de responsabilização: buscando o diálogo. In: BAUER, Adriana; GATTI, Bernadete Angelina. (orgs.). Vinte e cinco anos de avaliação de sistemas educacionais no Brasil. Florianópolis: Insular, 2013. p. 100-122.

DANTAS, Jéferson Silveira. Construir espaços coletivos de esperança em tempos de discurso de ódio. Florianópolis: Insular, 2017.

DANTAS, Jéferson. Competências e habilidades e a formação docente no contexto das leis 5.692/1971 e 9.394/1996 em Santa Catarina. Rio de Janeiro: CBJE, 2009.

DARDOT, Pierre; LAVAL, Christian. A fábrica do sujeito neoliberal. In: DARDOT, Pierre; LAVAL, Christian. A nova razão do mundo: ensaio sobre a sociedade neoliberal. Tradução de Mariana Echalar. São Paulo: Boitempo, 2016. p. 321-376.

FERNANDES, Claudia de Oliveira. Avaliação, currículo e suas implicações: projetos de sociedade em disputa. Revista Retratos da Escola, Brasília, v. 9, n. 17, p. 397-408, jul./dez. 2015.Disponível em: http://retratosdaescola.emnuvens.com.br/rde/article/view/588. Acesso em: 17 set. 2018.

FREITAS, Luiz Carlos de. Relatório do BM é revisado por Nelson Amaral. Blog Avaliação Educacional, [S.I.], 2017. Disponível em: https://avaliacaoeducacional.com/2017/11/27/relatorio-do-bm-e-revisado-por-nelsonamaral/. Acesso em: 17 set. 2018.

FREITAS, Luiz Carlos de. Caminhos da avaliação de sistemas educacionais no Brasil: o embate entre a cultura da auditoria e a cultura da avaliação. In: BAUER, A; GATTI, B. 
(orgs.). Vinte e cinco anos de avaliação de sistemas educacionais no Brasil. Florianópolis: Insular, 2013. p. 120-147.

FREITAS, Luiz Carlos de. Escolas aprisionadas em uma democracia aprisionada: anotações para uma resistência propositiva. Revista HISTEDBR On-line,Campinas, v.18, n.4, p.906926, out./dez. 2018.DOI: 10.20396/rho.v18i4.8654333. Disponível em: https://periodicos.sbu.unicamp.br/ojs/index.php/histedbr/article/view/8654333. Acesso em: 17 set. 2018.

FRIGOTTO, Gaudêncio (org.). Escola sem partido: esfinge que ameaça a educação e a sociedade brasileira. Rio de Janeiro: UERJ, 2017.

FRIGOTTO, Gaudêncio. Educação para a ‘inclusão' e a ‘empregabilidade': promessas que obscurecem a realidade. In: CANÁRIO, Rui; RUMMERT, Sonia Maria (orgs.). Mundos do trabalho e aprendizagem. Lisboa: Educa, 2009, p. 61-78.

HOBSBAWM, Eric. Era dos extremos: o breve século XX: 1914-1991. 2. ed. Tradução de Marcos Santarrita. São Paulo: Cia das Letras, 2009.

LEHER, Roberto. Banco Mundial: ajuste regressivo e antidemocrático. Correio da Cidadania, [S.I.], 2017. Disponível em:http://www.correiocidadania.com.br/2uncategorised/12966-banco-mundial-ajuste-regressivo-e-antidemocratico. Acesso em: 17 set. 2018.

LIBÂNEO, José Carlos. O dualismo perverso da escola pública brasileira: escola do conhecimento para os ricos, escola do acolhimento social para os pobres. Educação e Pesquisa, São Paulo, v. 38, n. 1, p. 13-28, mar. 2012. Disponível em: https://www.scielo.br/j/ep/a/YkhJTPw545x8jwpGFsXT3Ct/?lang=pt\&format=pdf. Acesso em: 17 set. 2018.

LÖWY, Michael. O golpe de Estado de 2016 no Brasil. Carta Maior, [S.I.], 2016. Disponível em: https://www.cartamaior.com.br/?/Editoria/Politica/O-golpe-de-Estado-de-2016-noBrasil/4/36139. Acesso em: 14 mar. 2018.

MARICATO, Erminia. Para entender a crise urbana. São Paulo: Expressão Popular, 2015.

MOVIMENTO PELA BASE NACIONAL COMUM. Dimensões e desenvolvimento das competências gerais da BNCC. [S.I.], 2018. Disponível em:

https://movimentopelabase.org.br/wp-

content/uploads/2018/03/BNCC_Competencias_Progressao.pdf. Acesso em: 17 set. 2018.

PIMENTA, Thiago Salgado Vaz de Lima. As implicações da Prova Floripa no trabalho docente. 163 f. 2018. Dissertação (Mestrado em Educação) - Programa de Pós-Graduação em Educação, Universidade Federal de Santa Catarina, Florianópolis, 2018.

SANTOS, Cláudio Félix (org.). Crítica ao esvaziamento da educação escolar. Salvador: EDUNEB, 2013. 
SANTOS, Jane Eire Rigoldi dos. Política de avaliações externas: a ênfase na questão das competências cognitivas e socioemocionais. 170 f. 2018. Tese (Doutorado em Educação) Programa de Pós-Graduação em Educação, Universidade Estadual Paulista Júlio de Mesquita Filho/UNESP, Araraquara, 2018.

SAVIANI, Dermeval. Teorias pedagógicas contra-hegemônicas no Brasil. Ideação, [S.I.], v. 10, n. 2, p. 11-28, jan. 2000. ISSN 1982-3010. Disponível em: http://e-

revista.unioeste.br/index.php/ideacao/article/view/4465. Acesso em: 17 set. 2018.

SCHULZ, Peter. O Banco Mundial contra-ataca. Jornal da Unicamp, [Campinas], 2017. Disponível em: https://www.unicamp.br/unicamp/ju/noticias/2017/11/27/o-banco-mundialcontra-ataca. Acesso em: 17 set. 2018.

SILVA, Márcio Magalhães da. A formação de competências socioemocionais como estratégia para captura da subjetividade da classe trabalhadora.170 f. 2015. Dissertação (Mestrado em Educação) - Programa de Pós-Graduação em Educação, Universidade Estadual de Maringá, Maringá, 2015.

SNYDER, Timothy. Sobre a tirania: vinte lições tiradas do século XX para o presente. São Paulo: Companhia das Letras, 2017.

SOUSA, Sandra M. Zákia L. Possíveis impactos das políticas de avaliação no currículo escolar. Cadernos de Pesquisa, [S.I.], n. 119, p. 175-190, jul. 2003. Disponível em: https://www.scielo.br/j/cp/a/SmhCBBnCzL3PB3QnbRbJKdf/?lang=pt\&format=pdf. Acesso em: 17set. 2018.

VAILLANT, Denise. Proyecto estratégico regional sobre docentes. [S.I.]: UNESCO: OREALC: CEPPE, 2011. Disponível em: http://ceppe.uc.cl/publicaciones/proyectoestrategico-regional-sobre-docentes. Acesso em: 17 set. 2018.

ZANARDINI, João. Ontologia e Avaliação da Educação Básica no Brasil (1990-2007).208 f. 2008. Tese (Doutorado em Educação) - Programa de Pós-Graduação em Educação, Universidade Federal de Santa Catarina, Florianópolis, 2008. 